\title{
SIMULATION AND REALIZATION OF SOME CMOS-TRANSCONDUCTOR VHF FILTERS
}

\author{
UMESH KUMAR* \\ EE Department, IIT Delhi, New Delhi-110016, India
}

(Received 18 J une 2001; In final form 13 August 2001)

\begin{abstract}
CM OS circuits for integrated analog filters at very high frequencies have been designed through PSPICE based on the Transconductance-C integrator. They have been implemented on the bread board and many filters i.e. LP, BP, Elliptic LP etc. are simulated and realized.
\end{abstract}

Keywords: VHF filters; CM OS circuits; Circuit simulation; Transconductor filters

\section{INTRODUCTION}

Current mode signal processing circuits have recently demonstrated many advantages over their voltage mode counterparts, including $B$ and width higher dynamic range and better suitability for the operation in reduced supply voltage environments (e.g. 3.3 volt). In addition they often lead to simpler circuitry and lower power consumption.

The transconductor is a crucial part of the design since it may limit the linearity, frequency response and noise, as applications in communication circuits and systems tend to call for more high frequency and even fully integrated designs. Engineers searched for a more suitable active element to provide the high gain without imposing frequency limitations. The output current rather than the output voltage is made proportional to the input voltage.

$$
\mathrm{I}_{\text {out }}=g_{\mathrm{m}} \mathrm{V}_{\text {in }}
$$

where $G_{m}$ is the transconductance.

The literature contains many useful designs [1-2]. Depending upon the technology chosen, the frequency range extends to $>50 \mathrm{M} \mathrm{Hz}$ (CM OS): $>500 \mathrm{M} \mathrm{Hz}$ (Bipolar) or even to $>1 \mathrm{GHz}$ $(\mathrm{G} a \mathrm{~A}$ s). Transconductor-C filters can be readily implemented and fully integrated from compatible with the remaining - often digital system - in any desired technology.

A nalog filters on chip in fully integrated form for operation in the $\mathrm{M} \mathrm{Hz}$ range is beginning to appear for use in video signal processing applications and computer disc drives.

*E-mail: umesh@ee.iitd.ernet.in 


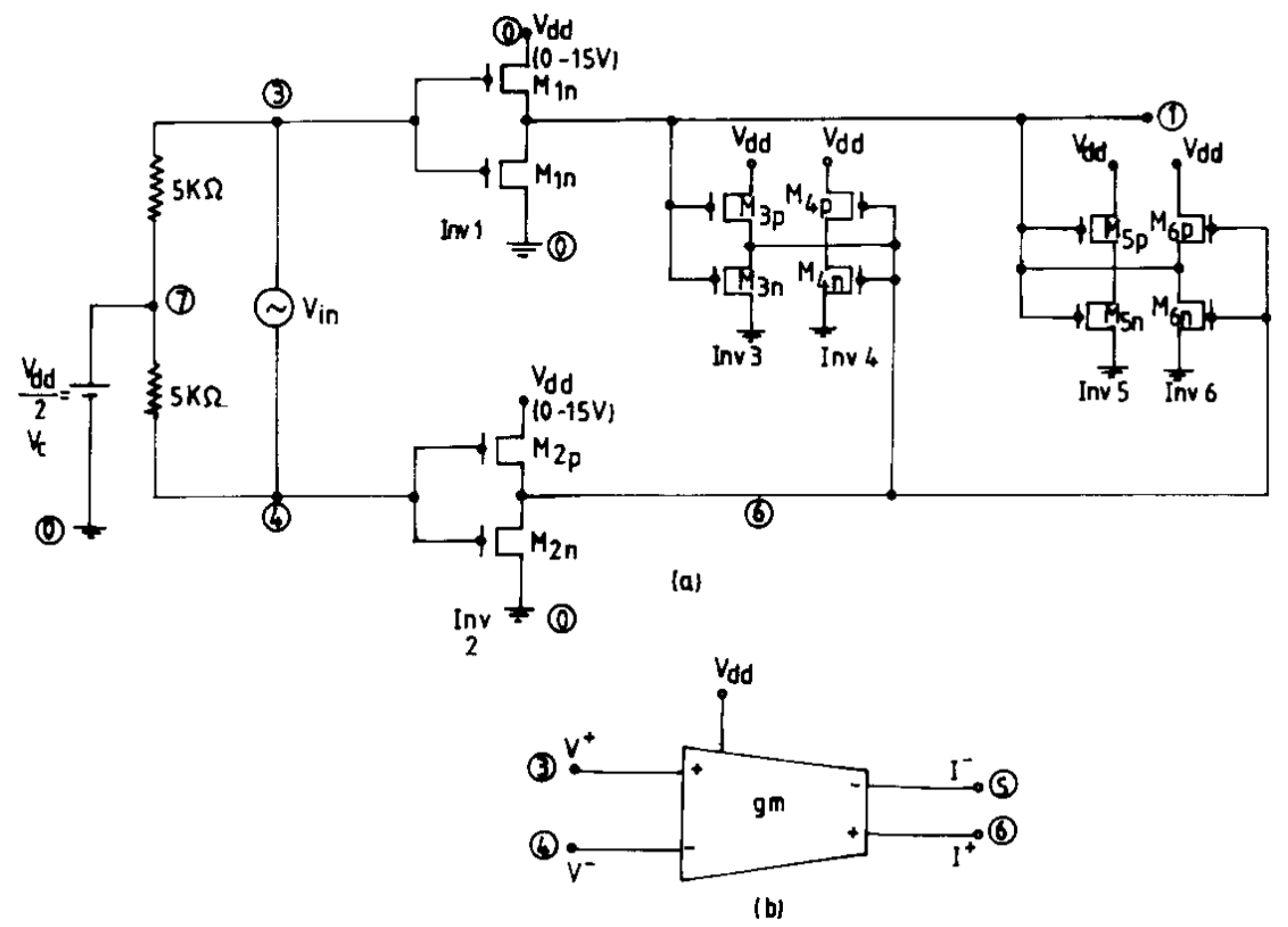

FIGURE 1

\section{VHF CMOS TRANSCONDUCTOR DESIGN}

The integrator is the main building block of integrated active filters. Here the integrator is implemented by a Transconductance element loaded with a capacitor. One of the major problems in a high-frequency active filter is the face error of the integrator $[3,4]$. It is desirable that the dc gain of the integrator is roughly $40 \mathrm{~dB}$ and the parasitic poles are located at least a factor of 1000 beyond the cut off frequency to avoid this. We have designed a completely fully balanced differential OAT (operational Transconductance amplifier) using the commercially available clips CD 4069 CM OS invertor circuits (Fig. 1).

\section{VHF CMOS FILTERS DESIGN, SIMULATION AND REALIZATION}

Various VHF filters, BP (Fig. 2), LP (Fig. 3) and elliptic LP (Fig. 4) were designed using the CMOS differential transconductor (Fig. 1) and simulated through PSPICE. The CMOS differential transconductor units have bandwidth in the $\mathrm{MHz}$ region due to the absence of internal nodes. The linearity is good and transconductance can be found by means of supply voltage.

The current base transconductors comply with the safety requirements of low chip area and high frequency operation, which is required today [5]. The design is based on identical transconductors and grounded capacitor and hence is extremely simple. Transparent and IC layout and processing possibilities exist. 


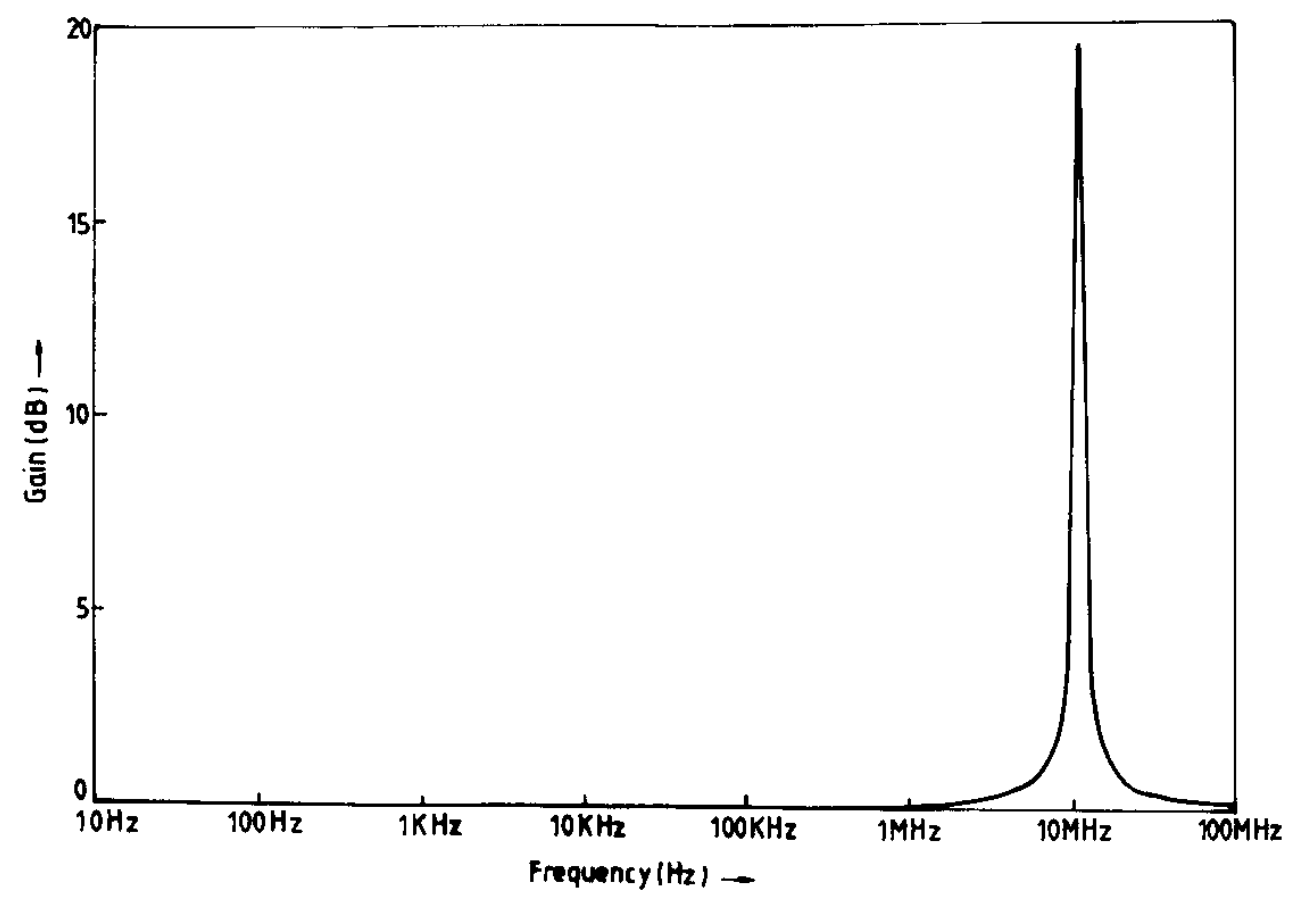

FIGURE 2

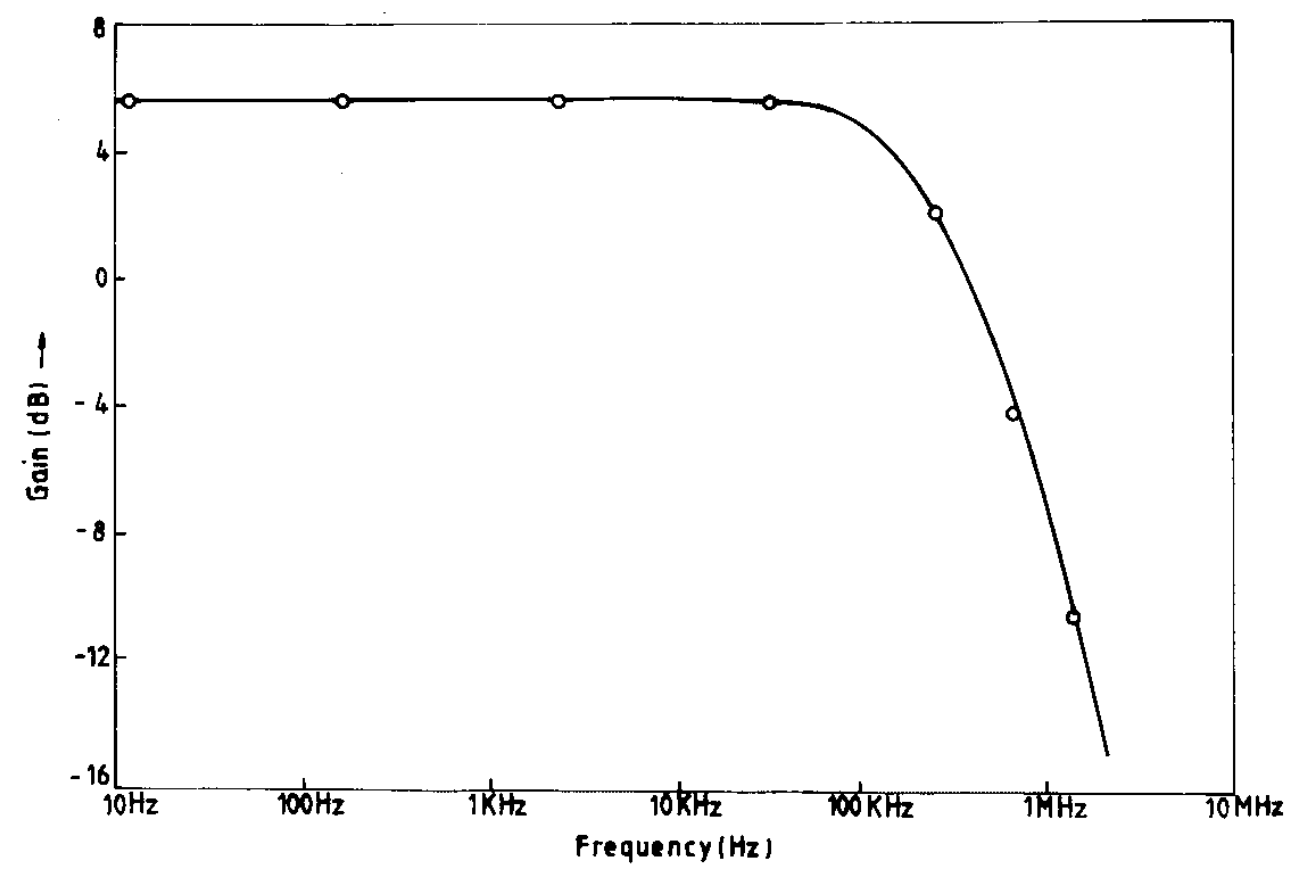

FIGURE 3 


\section{CONCLUSION}

Circuits for integrated filters at very high frequencies in fully CMOS technology have been designed and simulated using PSPICE and implemented on the breadboard.

The problem faced is that of the real ability and stability of filter parameters in changing conditions. Un-clip automatic tuning and controlled scheme can solve this problem. Future work is possible by the design and implementation of control circuitry of better performance of the filters.

\section{References}

[1] Schaumann, R., Ghausi, M. S. and Laker, K. R. (1990). D esign of Analog Filters: Passive Active-RC and Switched Capacitor. Prentice Hall, Englewood Cliffs, New Jersey, USA.

[2] Park, C. S. and Schaumann, R. (1986). Fully integrated analog filters in CM OS technology. ISCAS, 1161-1164.

[3] K horramabadi, H. and Gray, P. R. (1984). High frequency CM OS continuous-time filters. IEEE. J. Solid State Circuits, SC-19(6), 939-948.

[4] De Heij, W. J. A., Seevinck, E. and Hoen, K. (1989). Practical formulation of the relation between filter specifications and the requirements for integrator circuits. IEEE Trans., CAS-36, 1124-1128.

[5] Khoury, J. M. and Tsividis, Y. P. (1987). A nalysis and compensation of high-frequency effects in integrated M OSFET-C continuous-time filters. IEEE Trans., CAS-34, 862-875. 

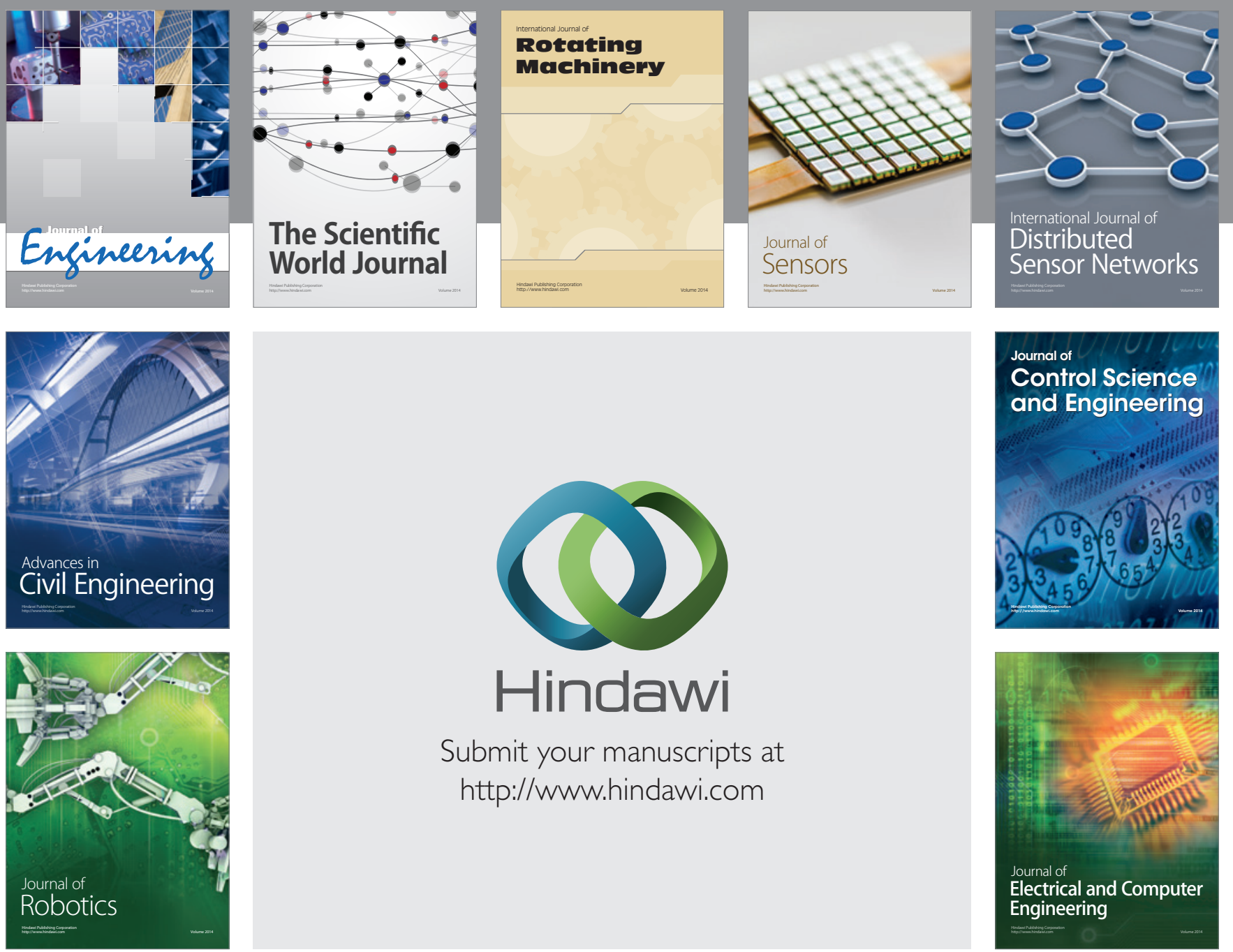

Submit your manuscripts at

http://www.hindawi.com
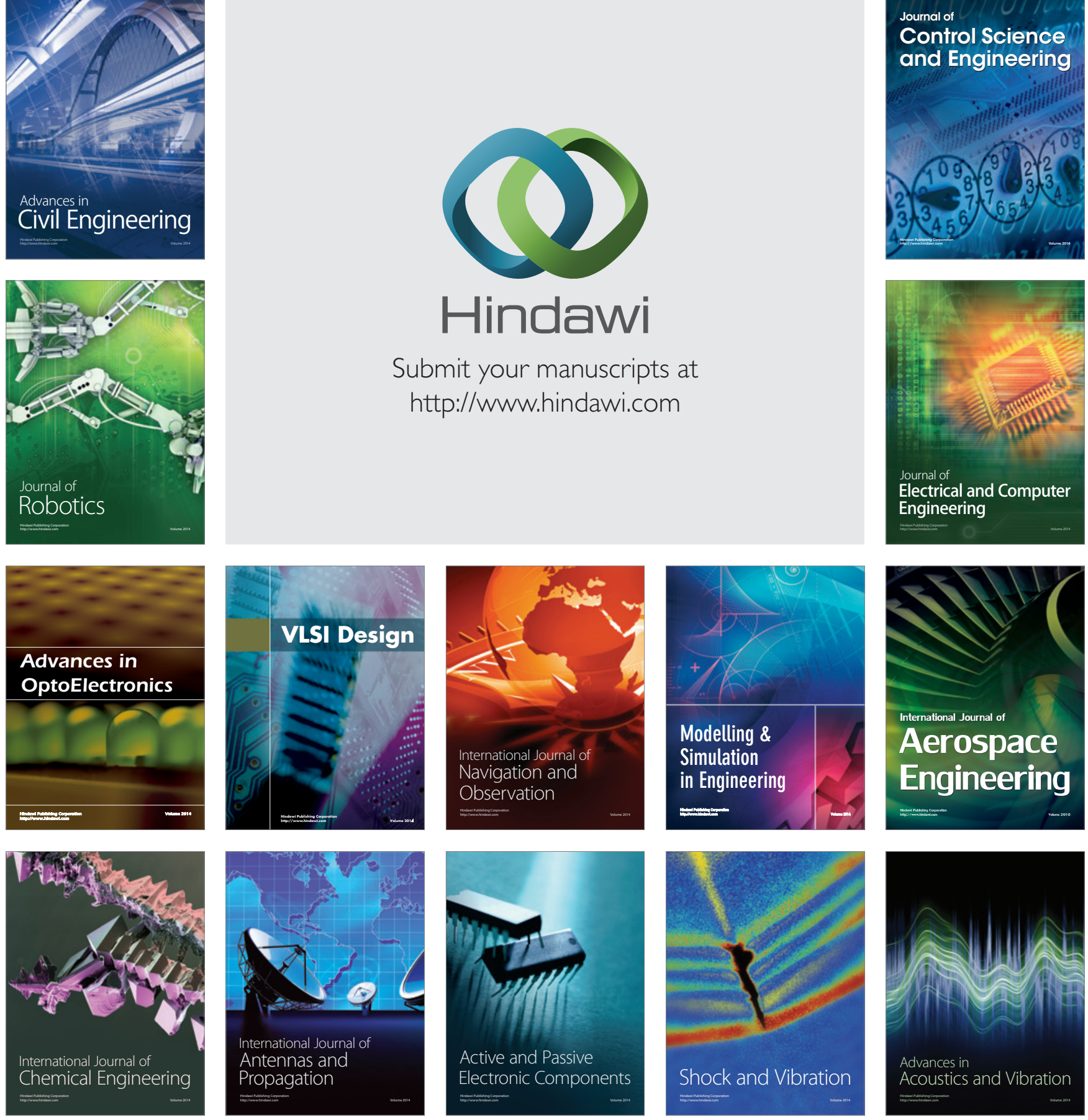